\title{
Trade-off between Safety of Construction Workers and Economy in Backdrop of Covid-19
}

\author{
Ajaya M. Ramachandra',2, Rajiv Gupta2," \\ ${ }^{1}$ School of Construction Management, National Institute of Construction Management \& Research, Dulhera, \\ Bahadurgarh-Jhajjar, State Highway No. 22, Bahadurgarh 124507, Haryana, India \\ ${ }^{2}$ Civil Engineering Department, Birla Institute of Technology and Science, Pilani 333031 , Rajasthan, India \\ *Corresponding author: E-mail: rajiv@pilani.bits-pilani.ac.in
}

DOI: 10.5185/amlett.2020.081542

The Indian Construction industry, which contributes to $8-10 \%$ of the country's GDP, is suffering from an unprecedented crisis in the wake of the COVID-19 pandemic. The Indian Government is facing a strict tradeoff between preventing and containing the spread of Coronavirus on the one hand and revitalizing the economic activities which have come to complete halt/resumed partially depending on the zone to which an area depends on the other side. Impact of the lockdown on the industry, stimulus measures announced by the Indian Government, and some other actions recommended by Industry experts' for the revival of the Construction sector are discussed in this paper. The detailed specific guidelines to be adopted by the site personnel for safely resuming the site work are presented for the benefit of Industry practitioners. Experimental study results on the stability of SARS-CoV-2 virus on surfaces of different materials are presented. Also, the potential and suitability of Construction material and technology for overcoming the current challenges posed by the pandemic is discussed. The main objective of the paper is to understand the current precarious situation of the Construction industry and the strategies to overcome it for moving forward.

\section{Introduction}

COVID-19 plague has challenged the economic and social development of many countries, including India. India's first case of COVID-19 identified on January 30, 2020. Analysis of the first 50 COVID-19 cases shows that the majority of them had a travel history to an already affected country, and the remaining are because of local transmission through people having the travel history [1]. The transmission rate of COVID-19, i.e., the average number of new infections from an already infected person, is assessed based on the reproduction number $\left(\mathrm{R}_{0}\right)$ of the COVID-19 virus. If $\mathrm{R}_{0}$ is greater than or equal to 1 , the number of infections will escalate; otherwise, the transmission is likely to perish over a while. From the comparative study of the estimate of $\mathrm{R}_{0}$ using different approaches, the author(s) have estimated mean $\mathrm{R}_{0}$ at the $3^{\text {rd }}$ stage of infection, i.e., Community spread phase to be $3.28[2]$.

In an interview to the BBC in Delhi, Dr. Laxminarayan, director of the Centre for Disease Dynamics, Economics and Policy has said that if the same mathematical models applied in the US or UK were used to India, the country could be dealing with about 300 million cases, of which about four to five million could be severe. India is under-equipped to deal with, as there are roughly only 70,000 to 1, 00,000 ICU Beds all over the country [3].

The infection has become intractable because of nonspecific features of the disease, long incubation period varying from 2 to 14 days, no sign of any symptoms during the incubation period, transmission from asymptomatic people, tropism for mucosal surfaces such as the conjunctiva, prolonged duration of the illness and transmission even after clinical recovery. When India had reported only 29 cases by 5/March/2020, Mr. Singhal, T. had suggested practical points like checking travel history of patients with a respiratory symptom, avoiding nonessential international travel, etc., to contain the outbreak in our country [4].

The number of cases as on 24/June/2020 in the top cities of India where the real estate sector is more predominant are as tabulated (Table 1) below [5]:

Table 1. Total number of cases \& containment zone in top cities of India.

\begin{tabular}{lccccc}
\hline City & $\begin{array}{c}\text { No. of } \\
\text { confirmed } \\
\text { cases }\end{array}$ & $\begin{array}{c}\text { No. of } \\
\text { active } \\
\text { cases }\end{array}$ & $\begin{array}{c}\text { No. of } \\
\text { recovered } \\
\text { cases }\end{array}$ & $\begin{array}{c}\text { No. of } \\
\text { deceased } \\
\text { cases }\end{array}$ & $\begin{array}{c}\text { No. of } \\
\text { Containment } \\
\text { zone as on } \\
\text { 04/June/2020 }\end{array}$ \\
\hline Mumbai & 68,410 & 29,982 & 34,576 & 3,844 & 706 \\
Delhi & 66,602 & 24,988 & 39,313 & 2,301 & 219 \\
Pune & 16,907 & 7,141 & 9,142 & 624 & 66 \\
Chennai & 44,205 & 18,893 & 24,670 & 642 & 157 \\
Hyderabad & 6,877 & 6,549 & 305 & 23 & 130 \\
Bengaluru & 1,505 & 996 & 435 & 73 & 49 \\
\hline
\end{tabular}

By looking at the number of cases in Mumbai, Delhi and Pune, it seems that the construction activities in these cities will not see complete relief anytime soon.

Ministry of Health \& Family Welfare (MoHFW), Government of India is regularly releasing clinical and nonclinical guidelines and protocols based on the latest evidence. In the interest of public health, Indian government first intervened on $3^{\text {rd }}$ March 2020 making 


\section{Advanced Materials Letters www.vbripress.com/aml}

announcement of travel ban on four countries namely China, Italy, South Korea and Iran. The first lockdown by the Central government was announced on $23^{\text {rd }}$ March 2020. In between the above two events, there were many measures taken across different states in the interest of public health and control measures which are being summarised in a table by the authors [6].

Misinformation and social stigma are another challenge added to the pandemic in the current situation. With the rampant circulation of information about COVID19 , people may take undue advantage of the situation and spared false information with an ulterior motive. In a scientific study on the infodemics of COVID-19 in India, it has been documented that misinformation is widespread even among doctors, with $68.2 \%$ of participants having received misinformation, and $50 \%$ of participants felt that it was difficult to discriminate between correct and incorrect information about COVID-19. The leading sources of misinformation are from social media, followed by family and friends circle [7]. In order to address this issue of spreading misinformation and stigma related to COVID-19, Ministry of Health \& Family Welfare (MoHFW), Government of India has come up with a guide for the public to follow [8] and also a video of the same [9].

\section{Impact on construction industry \& strategy to overcome}

\section{Impact on labor force and Blue/white-collar jobs}

The lockdown has held up all activities and severely impacted the construction sector, with some laborers stationed at the construction site where developers are taking care of their needs and remaining, have already moved to their native place. Extension of Lockdown on construction sites may lead to an unprecedented challenge of the re-acquiring labor force as monsoons are approaching, and there are high chances of the labor movement for harvesting purposes. To ease this difficult situation, the National Association of Real Estate Developers Council (NAREDCO) has suggested lifting the lockdown partially on the construction site to continue the work while following all the safety guidelines given by the Government. Also, a monetary relief package of $\$ 200$ billion has been sought from the Government to ease the impact of COVID19 [10].

The finance minister Ms. Nirmala Sitharaman has announced a welfare fund of Rs. 310 billion for building and other construction workers and the guidelines for utilization of the fund will be given to state governments. The announced scheme is expected to benefit 3.5 crore registered building and construction workers. Many real estate builders and developers have lauded and welcomed this move from the Centre as the workers are the one who is going to suffer the most as they are mostly dependent on daily wages [11]. Ministry of Labour and Employment came up with a notification to transfer the welfare cess fund amount in the accounts of workers through DBT mode [12].
In an opinion poll conducted by Construction World Magazine, about $2 / 3^{\text {rd }}$ of respondents feels that despite the Finance Minister announcement of a welfare fund of Rs 310 billion to be set aside for building and other construction workers, the lockdown has a long term impact on construction and infrastructure projects in India, considering that construction workers have left sites to return to their villages [13].

In a webinar on "Roads to recovery" conducted by Construction Magazine, Mr. Sandeep Garg - MD \& CEO of Welspun Enterprises Ltd has said that once the lockdown was lifted, laborers staying back at the site will tend to visit their villages because of family pressure. Even if the transportation problem is solved across the country, gathering back the labor force becomes an issue, and it would take some time for business to grow as usual. By that time, we would see the onset of monsoon. It is going to be a long $\mathrm{U}$ recovery than $\mathrm{V}$ for the Industry. At best, it is $\mathrm{U}$ recovery; in the worst-case scenario, it would be $\mathrm{W}$ recovery or L recovery if another COVID-19 attack takes place after resuming work [14].

The real estate sector is also likely to see job losses and pay cuts because of the loss of around 1 lakh crore money due to lockdown. The number of job losses depends on the period of lockdown. Sooner the lockdown is lifted lesser will be the pay cuts and job losses. NAREDCO President Niranjan Hiranandani said: "There will be an obvious impact on sales, and that, in turn, will impact the profitability of business organizations. So, a pay cut might be the first reaction across business organizations; some job losses might be the second" [15].

\section{Impact on logistics and construction material, equipment and human resources}

In construction works, different inventories are purchased for a particular period, like cement inventory would not be stored for more than 10-15 days. Even if the lockdown is lifted, logistics becomes a significant problem as vendors may not be able to get the drivers to supply construction materials to the site. Construction activities can come back its normalcy if the transportation industry also opens up completely.

Mr. Hardik Agarwal, Executive Director of Dinesh Chandra Agarwal Infracon Ltd. in a webinar on "Roads to recovery" conducted by Construction Magazine had put forth an idea asking for the Government to allow interstate migrant laborers to cross state borders with safety checks and measures so that it facilitates the construction work to begin and also help the manufacturing industry to gather drivers for the supply of inventories to the industry for the smooth running of construction projects [14].

Because of the Lockdown, Cement has been kept idle for months, and there is a fear in contractors and even cement manufacturers and vendors that the stock may become unusable as cement starts to deteriorate by $20 \%$ within three months of its manufacturing [16]. 


\section{Advanced Materials Letters www.vbripress.com/aml}

\section{Financial impact}

The real estate and infrastructure sector were suffering even before COVID-19 and a rescue package of Rs. 200 billion had been announced for unfinished projects [17]. Report by real estate consultancy firm JLL says Institutional investment into India's real estate sector has declined sharply in the January- March 2020 period, dropping 58\% year-on-year, and the recent Covid-19 outbreak was one of the biggest reasons for the decline [18].

Mr. Pratap Padode, Editor-in-Chief of the Construction World Magazine, in his open letter to Smt. Nirmala Sitharaman, Hon'ble Minister of Finance, has given some recommendations for easing the financial problem which includes Interest waiver on the mobilization advance, Release of past six month's retention money, pending bills to be paid within seven days, no deduction on RA bill for the next few months, Zero stamp duty for six months and removal of property tax for the next one year. Postponement of all EMI's payable by homebuyers as well as developers for the next three months etc. [19]. Even though the above recommendations may smoothen the cash burden for developers, contractors, and home buyers, however, when it comes to implementation, not all suggestions are in the hands of the Government. For example, the release of retention money, pending bills payment, and no deduction in RA bills may not get implemented from top to bottom level of the chain even if the Government may bring this relief in place. It may not be possible to get it implemented in non-government projects.

\section{Impact on allied Industrial sectors}

Even though lockdown is left out from power generation, steel processing, fertilizers, fuel, drugs, petroleum products, and mining sectors and production continues, there is a significant fall in the volume of production owing to less demand, shortage of laborers, and disruption of supply-chain logistics. Consumption of oil products declined by $17.8 \%$ in March 2020 compared with March 2019, which represents the most significant decline since monthly data on petroleum usage were released in 2004. In March 2020, electricity generation cut down by 8.8 percent relative to March 2019. Demand also constrains the production of steel. According to the Joint Plant Committee (JPC), the gross output of finished steel recorded 27.4 percent y-o-y decline in March 2020, the worst drop since the beginning of the series in 1995. Only 6.7 million tonnes of finished steel was produced during March 2020, wherein the average monthly production during 2019-2020 ranged between 8 to 9 million tonnes. Fig. 1, Fig. 2 and Fig. 3 show Production of Petroleum products, Electricity and Finished Steel Y-o-Y (\% change) respectively. In the unorganized industries related to the Construction Industry, it is evident that there would be an even higher percentage of decline in production compared to the sectors mentioned above. [20]

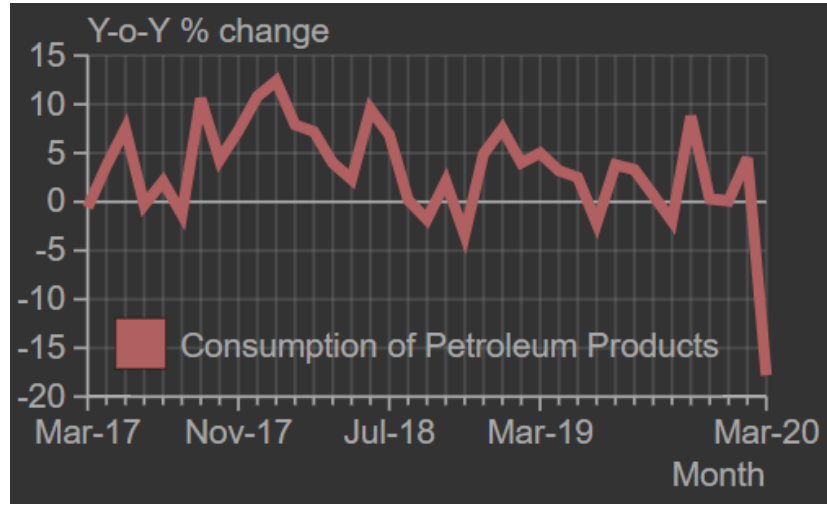

Fig. 1. Y-o-Y \% change wrt Consumption of Petroleum Products (Source: CMIE data).

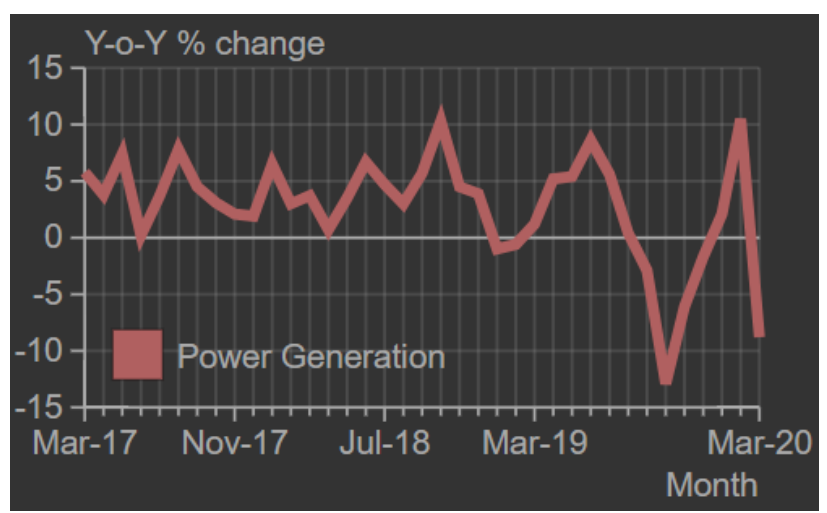

Fig. 2. Y-o-Y \% change wrt Power Generation (Source: CMIE data).

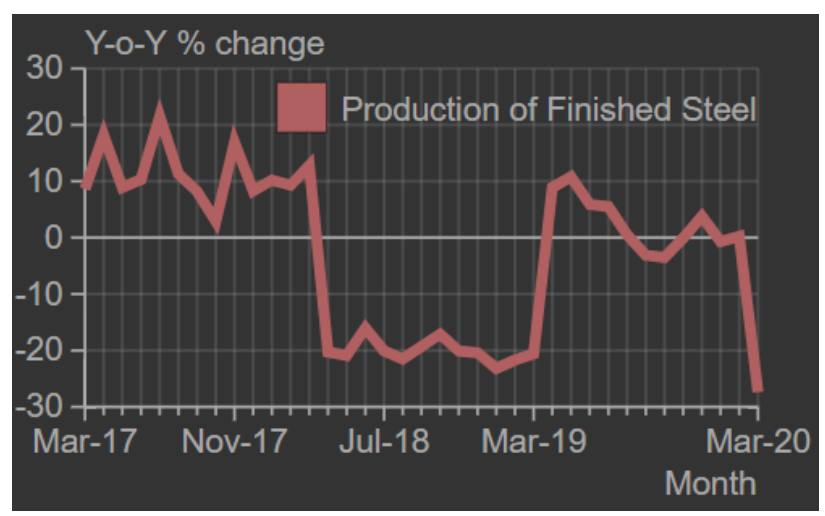

Fig. 3. Y-o-Y \% change w.r.t. production of finished steel (Source: CMIE data).

\section{Occupational risk and spread of the virus}

Research on transmission dynamics of Coronavirus in Wuhan, China had confirmed that before the closure of Huanan Seafood Wholesale Market on January 1, 2020, a significant proportion, i.e., $55 \%$ of cases were related to the market. Post the closure of the wet market, health care workers (HCWs) were identified as a high-risk group to get the infection [21]. Everyone involved in a wide variety of occupations should be alert to the risk of COVID-19, and proper infection control practices can protect the groups. Mental health support, which is often overlooked, should also be given to workers in addition to social distancing [22]. In a survey of employees in Hong Kong, 88\% of workers reported significantly increased stress levels 


\section{Advanced Materials Letters www.vbripress.com/aml}

because of the lack of adequate workplace policy for prevention and control of COVID-19 and deficiency in the supply of protective equipment [23]. Hence the occupational risk of COVID-19 is evident from the above studies, and to protect the workers on construction sites, it is crucial to clearly define guidelines and strictly implement the same in the interest of the lives of people involved in work.

It is essential to know how the Coronavirus spreads and educate the laborers/workers regarding it to emphasize the significance and seriousness of following the guidelines at the construction site. It is best to display these causes for the spread on placards. Coronavirus pathogens are not new as seven types of coronaviruses have been reported so far including the latest one SARS-CoV-2. The current pandemic is the fourth major outbreak by corona virus and first of its kind to break the geographical barrier challenging the entire world [24]. However, the study about how SARS $\mathrm{CoV}-2$ is spreading is still on and not yet very clear. For now, the understanding is that spread takes place in two ways namely by person-to-person contact and by touching contaminated objects or surfaces.

The virus is thought to spread between people who are in close contact with one another and through respiratory droplets produced when an infected person coughs, sneezes or talks, the droplets can land in the mouths or noses of people who are nearby or possibly be inhaled into the lungs. It may also spread by touching a surface or object that has the virus on it and then touching their mouth, nose, or possibly their eyes. It has been established that while eating and normal talking, droplets from the mouth can travel a distance between 1 and $2 \mathrm{~m}$ (3-6 feet). But with strong coughing and sneezing it could reach 4-8m (12-24 feet). Therefore a reasonable social distance is advised during any epidemic disease [25].To avoid person-to-person contact spread - social distancing and wearing of face mask are the remedies and to avoid spread through a contaminated surface - washing hands, disinfection, disposal of used Personal protective gears, avoiding touching nose and eyes, sanitization of an area/workplace occupied by workers are to be followed [26]. Coronavirus disease is mostly transmitted by contact or droplet transmission, and appropriate use of personal protective equipment (PPE) significantly reduces the risk of viral transmission. [27]

\section{Guidelines for resuming construction site work}

On March 24, the Government of India ordered a nationwide lockdown for 21 days following which the construction industry comes to a standstill. Owing to the nature of construction work wherein workers do work with some distance and they are exposed to the natural environment rather than working in ACs environment like in IT Industry, it is possible to restart the construction activity. It is riskier to keep the laborers in labor hutment as the chances of getting infected are more compared to working at a site where social distancing is naturally maintained because of the nature of the work. However, in areas where there is a big gathering like concreting work, some arrangements have to be made to carry out the work by maintaining social distancing or mitigating actions should be adopted, as mentioned under specific guidelines below. Incompetent management and lack of preparedness has affected at least 2000 people and claimed 11 lives in the recent Vizag gas leak mishap from LG Polymer factory [28]. The Vizag mishap should serve as a lesson to understand and implement safety guidelines in the construction sites for avoiding similar disasters in the lives of workers.

On April 14, 2020, India extended the Lockdown until April 3, 2020. The union home ministry issued a guideline effective from April 20, where developers can resume construction activities in projects situated in noncontainment zones and within the limit of municipal corporations or municipalities, where workers are available on-site, and no workers are required to be brought in from outside [29]. Though this move is a relief to the real estate sector, however continuous construction activity can take place only after the logistic problem is solved, which is a very big challenge in the current scenario. Also, construction work without materials like cement, steel, electric fixtures etc., is not possible, and the Government has not allowed all such supporting industries to function until May 3, 2020. The Government has announced a further extension of lockdown for two weeks till May 17.

\section{General guidelines}

Until a vaccine is discovered for treating the disease, prevention and control shall be the best approach for handling the current situation. Based on the research, the authors [30] had given general instructions for COVID-19 risk management to minimize the spread of COVID-19 in workplaces. General guidelines for Prevention and control includes educating workers about COVID-19, Stay home/quarantine in case of symptoms/suspected infection respectively, wash hands with soap/alcoholic solutions, maintain social distancing. Maintain cleanliness of the surface, avoid sharing of objects, ensure workplace ventilation and do not recommend unnecessary PPE. Based on the systematic review and meta-analysis, it has been established that there is an $82 \%$ reduction in the risk of contracting the disease if a physical distancing of $1 \mathrm{~m}$ or more is maintained [31]. NAREDCO under the guidance of Ministry of Housing and Urban Affairs (MoHUA), Govt. of India had come up with standard operating procedure (SOPs) and guidelines for the safety of construction workers and insisted the Government lift the ban on work at construction sites to continue the work while following the directions. The document containing the protocol to be followed are divided under three categories; namely, (i) General guidelines - which is applicable for everyone (ii) Guideline for Workers and (iii) Guidelines for Material, Tools, Machinery, Vehicles, etc. The SOPs clearly describes the do's and don'ts under the above three headings and also recommends for the deployment of a Site Safety Representative (SSR) to ensure strict enforcement of the safety guideline [32]. 


\section{Advanced Materials Letters www.vbripress.com/aml}

\section{Specific guidelines}

Though the Government has come up with guidelines, it talks about general precautions to be adopted. It doesn't describe in detail about the protocol to follow for specific activities and situations like Entry and exit of personnel to the site, handling of construction equipment and material, use of Canteen area in site, use of toilet area, To and fro travel arrangement for laborers, etc. Therefore to overcome these drawbacks and to do the job of Contractor/Client implementing the guidelines easy. Specific instructions for different activities involved in the site are being studied from various resources [32-36] and are presented below under different headings.

\section{Signage and markings:}

Below lists out different signage to be adopted on-site;

(i) Do's and don'ts' to be followed by workers like social distancing, covering face before sneezing, wearing a face mask, sharing of objects, etc.,

(ii) Precautions for control and prevention of the spread of the coronavirus.

(iii) How to wash hands/use sanitizer?

(iv) How to wear and discard protective gear?

(v) Steps to be followed if anyone becomes ill should be displayed.

(vi) Symptoms of COVID-19 and knowledge about how it spreads should be displayed.

(vii) Information and checklists on regular cleaning and disinfecting activities should be made available to concerned persons.

(viii) The contact number of Doctor-on-duty or Supervisor for reporting any medical issue should be displayed.

(ix) Marking on ground/floors describing the travel path, seating place, etc., should be adopted wherever necessary.

\section{Travelling to and fro to work}

Traveling to and fro to work is inevitable as work from home is not practical for jobs like construction activities. Therefore it is important to clearly define the guidelines regarding how workers should and should not travel to work for containing the spread of the virus. However, in general, in construction projects, the majority of the labor force are migrant workers. They would be staying within the construction site or at a small distance away from the site. Therefore generally the need for the use of public transport doesn't arise. Specific guideline to be adopted regarding travel arrangement are as follows;

(i) Wherever possible workers should travel alone using their transport.

(ii) For Workers staying outside (generally nearby) special transportation facilities will be arranged without any dependency on the public transport system.

(iii) Journeys should be shared with the same set of individuals in the same vehicle operated by the same driver. (iv) Proper ventilation (i.e., keeping the windows open) should be maintained in the vehicle

(v) People should be seated in a manner social distancing is maintained, and every individual faces away from each other.

(vi) The vehicle should be cleaned regularly using gloves and standard cleaning products, with particular emphasis on handles and other areas where passengers may touch surfaces

(vii) In the case of a site with a large workforce, stagger the working hours to reduce congestion at the site entry and exit points and also in the workplace.

(viii) Prepare a travel plan in advance on how if someone taken ill would get back to home/hospital.

\section{Site entry and exit of personnel}

(i) Mandatory thermal scanning for fever at Entry and exit points. If anyone leaves and re-enters the site during the shift, re-screening of the individual will be done before re-entry into the worksite.

(ii) Provide hand cleaning facilities, preferably touch-free facilities at entrance and exit points. The facility can be soap and water wherever possible or contactless hand sanitizer dispenser if soap and water are not available.

(iii) If possible, create a separate entrance and exit for site location.

(iv) Provide contactless biometric attendance system.

(v) Stop all non-essential entries.

(vi) Plan and stagger work timings or use more than one entry and exit point to the site so that there will not be a large gathering of workers at the entrance and exit location at one particular time.

(vii) Use floor marking and signage to follow the social distancing protocol.

\section{Handling construction equipment \& material}

(i) All vehicles and machinery entering the premise should be disinfected by spray mandatorily.

(ii) All construction material arriving at the site should be left idle for three days before use to ensure safe usage.

(iii) Drivers must remain inside their vehicle when loading and/or unloading construction materials.

(iv) Where drivers are required to exit their vehicles for handling any materials, they should wash or sanitize their hands before doing it.

\section{Conducting meetings:}

(a) As far as possible, go for a virtual online meeting using digital technologies.

(b) If a virtual meeting is not possible then follow the below guidelines for conducting meetings,

(i) Limit the number of people and only necessary meeting participants should attend.

(ii) Ensure social distancing before/during and after the meeting.

(iii) Keep the meeting as short as possible. 


\section{Advanced Materials Letters www.vbripress.com/aml}

(iv) Avoid humid places like the meeting point as the air can hold droplets for a more extended period if someone sneezes.

(v) Consider holding meetings in open areas where possible

(vi) Conduct the meeting with minimal oral communication and by using ppt or written communication.

Using lift

(i) One or two people should occupy the lift at any time, depending on the size of the lift area.

(ii) If two people/four people fit in a lift with a safe social distance, then they should occupy two opposite corners facing away from each other.

(iii) If there is a provision, designate elevators for "up" and "down" to avoid longer ride times.

(iv) Entry and exit pathways must be marked on the floor to avoid people getting close to each other during getting in or out of the lift area.

(v) Lift areas should be cleaned regularly, and emphasis should be given on lift operating buttons and the other regions where passengers would touch it frequently.

\section{Clean and disinfect frequently touched surfaces}

Cleaning and disinfecting for prevention and control of COVID-19 forms an important part for re-opening construction offices/sites and also for keeping the office continuously open in the future. A checklist has to be developed regarding what are the things to be cleaned and/or disinfected, how to clean and/or disinfect, how frequently, and what material to be used for cleaning and/or disinfection and the person responsible for these tasks. Here, cleaning refers to regular routine cleaning and doesn't involve disinfection using alcohol-based liquids, whereas disinfecting means the use of alcohol-based liquids recommended by $\mathrm{WHO} /$ Local government for killing the virus. Whether an area or objects needs to be cleaned and/or disinfected is decided based on the findings that Coronaviruses on surfaces and objects naturally die within hours to days. If an area/object is unoccupied/untouched for seven days or more, then it requires routine cleaning. Otherwise, it has to be cleaned first and then disinfected using $1 \%$ sodium hypochlorite or phenolic disinfectants as recommended by the Ministry of Health and Family Welfare.

Following are the specific guidelines for cleaning and/or disinfecting the workplace:

(i) Frequently touched surfaces may include workstations, construction equipment, doorknobs, handrails, lift operating buttons, switches, and electric boxes, telephone, Lift and hoist controls, etc. has to be cleaned and disinfected at least once in a day or between each shift.

(ii) If work takes place in 2 or 3 shifts, then between each shift, area and frequently touched objects have to be disinfected. (iii) Handling hard cash has to be avoided/limited by encouraging online transactions.

(iv) Workers must be discouraged from using other workers' phones, desks, offices, or other work tools and equipment, when possible. If necessary, clean and disinfect them before and after use.

(v) Disposable wipes should be provided to workers so that commonly used surfaces/objects can be wiped down before each use.

(vi) Identify a workplace coordinator who will be responsible for all COVID - issues.

(vii) Provide tissues and no-touch disposal receptacles if possible.

(viii) Place hand sanitizers/wash basin facilities in multiple locations to encourage hand hygiene especially outside the office or at entry and exit points of construction sites.

Lunch and snacks break

(i) Workers should be encouraged to bring their food; otherwise, the workplace canteen has to provide food with appropriate measures.

(ii) Depending on the capacity of the canteen area, Lunch/Break times should be staggered to reduce congestion and contact.

(iii) A distance of 2 meters should be maintained between users.

(iv) Payments should be taken by contactless card wherever possible

(v) Tables should be cleaned between each use

\section{Use of toilet area}

(i) Restrict the number of people using toilet facilities

(ii) Provide floor markings to ensure 2-meter social distancing between people when queuing

(iii) Wash or sanitize hands before and after using the facilities

(iv) Enhance the cleaning regimes for toilet facilities, mainly door handles, locks, and the toilet flush. Sanitary workers must use a separate set of cleaning chemicals, equipment, and procedures that are different from the other general cleaning procedures, as mentioned in the guidelines by the MoFHW.

(v) Provide suitable and sufficient covered trash bins for hand towels with regular removal and disposal.

Mitigation actions in unavoidable social distancing situations

Suppose social distancing guideline cannot be followed in full on a particular construction activity then following mitigation action should be taken to reduce the risk of transmission;

(i) Minimize the frequency and time workers are within 2 meters of each other to as small as possible. Keep this to 15 minutes or less wherever possible.

(ii) Minimize the number of workers involved in such tasks 


\section{Advanced Materials Letters www.vbripress.com/aml}

(iii) Workers should work side by side or face away from each other, rather than face to face.

(iv) Keep groups of workers that have to work within 2 meters together in teams and do not change workers within such teams to other teams of workers.

(v) Provide additional supervision to monitor and manage compliances.

\section{Other measures}

(i) Conduct employee awareness training on Prevention and control of COVID-19:

Many instances of people escaping hospitals or quarantine and hiding of travel history have been reported in India in the past. Fear of isolation and stigma attached to those who are being quarantined and isolated are some of the reasons for these behaviors [37]. Therefore, in order to make people understand the importance of isolation and quarantine, proper education and counselling have to be imparted to workers at the site to contradict the above factors from their mind.

(ii) Create a checklist of activities concerning prevention and control for easy tracking and implementation of safety measures

(iii) Assign roles and responsibility for the implementation of guidelines.

(iv) Provide covered trash containers for face masks near entrances/exits, elevators, and other common areas; empty and disinfect containers at least daily and more often if warranted.

(v) Impose a strict ban on spitting and consumption of Gutka, Tambaku, Paan, (local Tobacco products) etc.

(vi) Hospitals/clinics in the nearby area, which are authorized to treat COVID-19 patients, should be identified, and the list should be available at site all the time.

(vii) Launch a helpline number to address the psychological issues of workers because of the current pandemic.

(viii) Instruct workers to avoid contact with sick people and avoid going to the site if they are feeling sick, have a fever, cough, or shortness of breath. Such cases should be informed to the supervisor immediately.

(ix) Instruct and emphasize the importance of staying home if an employee is feeling sick.

(x) Form an emergency team at the workplace and train them on how to act if any employee shows COVID19 symptoms on site.

(xi) Formulate a procedure to be followed by an employee who was in close contact with an infected employee.

(xii) For tracing, make it mandatory to install AROGYA SETU Application on employees mobile.

\section{Virus life span on different material surfaces}

Man-made structures and features are collectively called by the term Built Environment (BE) which includes buildings, public infrastructures, vehicles and other human built spaces. Different BE is made up from different material(s) and as people use and exist within these BE day in and day out, it is important to understand the potential transmission dynamics of COVID-19 within these ecosystem. BEs assist as possible transmission vectors for the spread of COVID19 by making close interactions between individuals, by containing fomites (objects or materials that are likely to carry infectious diseases), and through viral exchange and transfer through the air [38]. Even though the virus has originated from animals and jumped into humans, the possibility of person to person transmission of the virus either through aerosolized viral particles through human respiration or through touching infected person or fomites have also been established in the study [39]. Therefore it is very crucial to understand the life of SARS-CoV-2 virus in aerosol and on surfaces of different materials for better planning to mitigate the pandemic.

The Authors [40] have analysed the aerosol and material surface stability of SARS-CoV-2 and compared it with closely related SARS-CoV-1 virus. Surface stability of the viruses were tested on surface of four different materials namely Plastic, Stainless steel, copper and cardboard. Though the Knowledge of the transmission dynamics of COVID-19 is currently developing, based upon the above studies on SARS-CoV-2, it seems likely that the virus can potentially persist on fomites ranging from a couple of hours to 5 days depending on the material. Based on Bayesian regression model to study the decay rate of the virus, it has been found that both viruses had an exponential decay in virus titer (i.e., number of viral particles capable to invade a host cell [41]) across all experimental conditions. The result across all experimental conditions using the two viruses is as summarized in Table 2.

Table 2. Infection capability of SARS-CoV-1 and SARS-CoV-2 for different materials (Source: [42]).

\begin{tabular}{lllll}
\hline Materials & \multicolumn{1}{c}{ SARS-CoV-1 } & \multicolumn{2}{c}{ SARS-CoV-2 } \\
\cline { 2 - 5 } & $\begin{array}{l}\text { Infection } \\
\text { capability } \\
\text { reduction (per } \\
\text { millilitre of } \\
\text { medium) }\end{array}$ & Duration & \multicolumn{1}{c}{$\begin{array}{c}\text { Infection } \\
\text { capability } \\
\text { reduction (per } \\
\text { millilitre of } \\
\text { medium) }\end{array}$} & Duration \\
\hline Aerosol & $10^{4.3}$ to $10^{3.5}$ & $3 \mathrm{~h}$ & $10^{3.5}$ to $10^{2.7}$ & $3 \mathrm{~h}$ \\
& TCID50 & & TCID50 & \\
Plastic & $10^{3.4}$ to $10^{0.7}$ & $72 \mathrm{~h}$ & $\begin{array}{l}10^{3.7} \text { to } 10^{0.6} \\
\text { TCID50 }\end{array}$ & $72 \mathrm{~h}$ \\
Stainless & $10^{3.6}$ to $10^{0.6}$ & $48 \mathrm{~h}$ & $10^{3.7}$ to $10^{0.6}$ & $48 \mathrm{~h}$ \\
steel & TCID50 & & TCID50 & \\
Copper & no viability & $8 \mathrm{~h}$ & no viability & $4 \mathrm{~h}$ \\
Cardboard & no viability & $8 \mathrm{~h}$ & no viability & $24 \mathrm{~h}$ \\
\hline
\end{tabular}

TCID50 stands for Median Tissue Culture Infectious Dose which signifies the concentration at which $50 \%$ of the cells are infected when a test tube or well plate upon which cells have been cultured is inoculated with a diluted solution of viral fluid. [43]. For the above experiment, Aerosols $(<5 \mu \mathrm{m})$ containing SARS-Vov-2 $\left(10^{5.25} 50 \%\right.$ TCID per ml) was generated with the use of a three-jet 


\section{Advanced Materials Letters www.vbripress.com/aml}

Collision nebulizer and fed into a Goldberg drum to create an aerosolized environment. From the above study it is evident that SARS-CoV-2 is more stable on plastic and stainless steel and was found up to 72 hours after application on surfaces though the virus titer greatly reduced on a logarithmic scale $\left(\log _{10}\right)$ from $10^{3.7}$ to $10^{0.6}$ TCID50 per millilitre of medium (i.e., from $\log _{10} 3.7$ to $\log _{10} 0.6$ which corresponds to reduction in viral load from 5,012 copies/mL to 4 copies/mL [44]). Whereas on Copper and Cardboard, there was no viable virus after 8 hour and 4 hours respectively.

Similar study should be carried out on other different commonly used construction materials like Bricks, Cement blocks, Concrete surface, Ceramics etc., so that the study results provide information for taking right decision with respect to prevention and control of SARS-CoV-2 virus. The above experimental results are obtained at $21-23^{\circ} \mathrm{C}$ and at $40 \%$ relative humidity, the same experiments has to be tested at other different environmental conditions to know the variation of results.

\section{Role of construction material and technology for tackling the problems of pandemic}

Construction material and construction technology are invariable interlinked in most of the cases. An innovative construction material would come with the requirement of a specific technology for its practical use, or conversely, an innovative construction technology comes with a particular requirement of construction material for its implementation. For example, monolithic construction technique used widely in the construction of mass housing and also in apartment buildings, comes with a reduced wall thickness. To implement this method of construction, we rely on modular formwork technology for achieving the monolithic building. In practice for implementing this method of construction and the modular formwork technology, we have to go for a concrete which can compact itself (i.e., self-compacting concrete) as it is not possible to use vibrator for compaction of concrete because of small thickness of walls and also as the entire building as to be constructed as a single unit. Hence in general, it is not possible to talk about either construction technology or construction material in isolation.

While Medical scientists across the globe are working day and night for covid19 vaccine, Doctors and Police have become frontline warriors in this pandemic war. Other fields of science can also contribute in this fight in their own way either directly for prevention and control or indirectly by ways of adaptations and contribution to the economy of the country. For example, material science can play a vital role in fulfilling the need for medical equipment like reanimation machines, valves, and respiratory aids, with the latest engineering technology like three-dimensional (3D) printing [45]. 3D printing can also be employed in the construction industry as it reduces the requirement of manpower which are scarcely available for the time being and also improves the efficiency of construction in terms of time, cost and wastage.
Precast concrete elements as construction material have many advantages which is the need of the hour in the current pandemic. One of the main advantage of using precast element is that the construction process can be mechanised in a controlled environment which reduces the labor requirements and also it can be executed throughout the year without any reliance on the monsoon. Prefabrication and Modular construction is also a potential solution as it can be carried out in shifts to cope up with the reduced productivity of laborers because of the current reduced number of workers and also because of social distancing and other guidelines to be followed at the site during execution. In order to overcome the problem of low productivity, low predictability, and lack of collaboration among different stakeholders, housing through prefabrication was recommended by the UK government [46]. To maximize the benefit and to overcome the current problems faced by the Construction Industry like labor shortage, low productivity of workers because of different guidelines to be followed at the site, upcoming monsoon season etc., it is best to combine Digital construction like Building Information Modelling (BIM) and Modular construction/Prefabrication. Even though there is an acknowledgment of various benefits of digital construction, developers have not invested sufficiently in the latest technology. The adoption of digital construction technologies will be a turning point for the success of the industry as a whole and also helps to adopt for the current challenge of maintaining contact-free work, hygienic site, and other covid19 protocols [47]. Ultimately if the technology is going to be used in an extensive way, the cost will be less expensive compared to the conventional way. In a webinar on "Construction Technologies - Post Covid19" organized by the Construction World Magazine - India, Mr. Sandeep Singh - MD Tata-Hitachi had opined that most of the contractors were not adopting advanced technologies in their construction equipment and only a few big contractors like L\&T, Shapoorji were using. Those who have adopted it have seen an overall benefit in terms of time, cost, and efficiency [48].

Antibacterial nanocoatings have the potential to prevent and control the growth of microorganisms on their surfaces and have widespread application in different fields like Marine systems, Food and packaging, Textiles, Medical related applications including Construction field. Statistics shows that most applications of antimicrobial nanocoatings are found in healthcare and medical sector followed by marine industry and construction industry [49]. Though initially in construction sector nanocoatings were used for improved mechanical strength, wear strength, and self-cleaning properties, recent studies have also discovered its effectiveness against biological attacks. For example, Green building paints made from Silver $(\mathrm{Ag})$ and $\mathrm{Cu}$ (Copper) nanoparticles shows excellent resistance against micro-organism growth, Use of Zinc Oxide $(\mathrm{ZnO})$ and Copper Oxide $(\mathrm{CuO})$ nanoparticles in coatings has increased the resistance of black pine wood against mold and fungi [50]. The authors [51] have patented the product 


\section{Advanced Materials Letters www.vbripress.com/aml}

in which, with the addition of biocidal agent such as copper oxide into a building article like cement, gypsum, wood/polymer and composite materials, it is possible to deter the growth and undesirable biological activities of mold, fungi, algae, mildew, bacteria, lichen and other such microorganisms. Though there are developments of advanced material to control and characterize the microbial ecology in the Built environment, its potential and suitability has to be assessed in fighting the current pandemic.

Indian construction industry is facing several troublesome challenges due to COVID-19, and once lockdown opens up, traditional approaches to overcome the problems are inadequate. Moving forward with whatever possible means available by keeping the constraints in mind is the solution to the current situation. Not all functions of the construction industry can work remotely, especially the construction activity at the site for which proper guidelines, as mentioned in the previous section, have to be adopted for overcoming the challenges posed by the current pandemic. However, for other functions of the industry, the current situation has provided a better opportunity and time to reflect upon the current practices in the construction industry and how we can modify and/or replace it with the help of technologies for overcoming the current challenge posed by the virus and also for overall improvement in terms of efficiency, construction time, construction cost, safety, etc.

With the help of technologies like communication tools, robotics, AI/Machine learning, Internet of Things, Drones, Building information modelling, etc., it is possible to carry out the work more efficiently and also remotely without the need for physical contact between different stakeholders. There are several potentials for each of the technologies mentioned above, and one or a combination of the above technologies can be adopted for project execution and management. It is a common practice to use BIM along with other technologies; however, generally there is a misconception that BIM is nothing but $3 \mathrm{D}$ modelling and $3 \mathrm{D}$ visualization. 3D modelling is only one function of BIM and there are other functions that can be achieved like clash detection, structural analysis, cost estimation, scheduling (4D), and facility management. To demonstrate the advantages of 4D BIM Model over the traditional approach, a survey based on the visual comparison between the above approaches was conducted. Based on the survey, $96 \%$ voted for the $4 \mathrm{D}$ BIM while $3.8 \%$ voted for the traditional approach [52].

To address planning, monitoring and quality and therefore the associated cost; the construction industry must pursue and implement innovative management techniques and organization. The advent of new pervasive technologies for managing and displaying digital geographical (natural and/or man-built) data has created a situation highly conducive to other technologies. The proposal is to incorporate BIM and GIS (Geographical Information System) for planning, and E-Construction and Quality Management (E-CQM) for monitoring construction and quality using IoT (Internet of Things) using Digital Photographs Processing (DPP) and World Wide Web (WWW). Developing BIM for the new/ ongoing projects and implementation of digital cameras at sites along with manual monitoring through reports and other imageries will be the initial step. Second step will be to upload the photographs and satellite imageries automatically and manually to the experts' site. This will be a continuous process till the project is complete. Developed software will process these documents and bring out the initial monitoring and quality issues to help the experts. Here the process would be made automated using Artificial Intelligence and Image processing. Experts sitting at their office will send their recommendations to the concerned clients. The proposed methodology will be very effective for planning, quality control, and monitoring during and after this pandemic. It is expected that the process will not be applicable only to monitor the important projects but it will also create a world wide database indicating the pitfalls in important projects [53].

\section{Opportunities of the current situation}

Covid-19 has hit the entire business story, especially the make in china's story. China- a massive provider of spares, components parts for all around the world with its strong manufacturing base has now about wholly disrupted. In terms of auto-components for construction equipment, Komatsu-which used to source spare parts from china has already moved most of the metal parts to Japan and Vietnam. JCB-UK has cut down its production by $25 \%$ owing to a shortage of spares from its manufacturing base in China. Daikin has moved its assembly of ACs to Malaysia. But this has offered an opportunity to India, but the question is whether the Indian Construction Manufacturing Industry is ready to take on this opportunity or not? [54]. Already around 1000 foreign firms, including Construction manufacturing industries, are planning to shift manufacturing to India and are currently engaged in discussions with authorities with 300 firms are actively pursuing it [55].

The Minister of Housing and Urban Affairs Mr. Hardeep Singh Puri had told to a group of developers at a webinar that the Government would look at issuing a digital signature protocol to facilitate digital sales of properties. Also, developers are looking at making use of visual and technological aids to provide 360-degree views of the properties to customers/bankers online for sale of the property and also for processing bank loans [56]. The present covid19 situation has given a chance to stop and rethink about the way things are carried out. It has given an opportunity to put the past behind and find out new normal suiting the current and future demand.

\section{Conclusion}

The overall study illustrates that economic impact is already visible, and the Government and the construction industry are adjusting itself to the current pandemic to emerge out of the existing financial pit. The money 


\section{Advanced Materials Letters www.vbripress.com/aml}

financed fiscal intervention by the Government is the most essential means to get the industry to the track. Construction is one industry that requires the support of core sectors and other connected sectors for its functioning. Hence for getting back to normalcy, India has to get free from this pandemic completely. However, there is also uncertainty as to how to tackle the problem post-COVID19. Digital construction and Precast technology are going to be the new normal for handling the current situation and even in the coming future.

For moving forward, COVID19 pandemic threat has to be addressed at 3 different levels: at the bottom level focusing on implementing Site operative specific guidelines/procedures to safely resume the work, at the middle level through the development of effective workplace policy by the Government as well as organizations and at the top level through informing policies and relief measures by the Government affecting the industry as a whole.

\section{References}

1. Rawat, M.; "Coronavirus in India: Tracking country's first 50 COVID-19 cases; what numbers tell.," India Today Magazine, 2020. [Online]. Available: https://www.indiatoday.in/india/story/ coronavirus-in-india-tracking-country-s-first-50-covid-19-caseswhat-numbers-tell-1654468-2020-03-12. [Accessed: 19-Apr-2020].

2. Liu, Y.; Gayle, A. A.; Wilder-smith, A.; Rocklöv, J.; J. Travel Med., 2020, 1.

3. Laxminarayan, D. R.; "India must prepare for a tsunami of cases' BBC News," BBC News, 2020. [Online]. Available: https:// www. bbc.com/news/av/world-asia-india-51962813/india-must-preparefor-a-tsunami-of-coronavirus-cases. [Accessed: 24-Apr-2020].

4. Singhal, T.; Indian J. Pediatr., 2020, 87, 281.

5. "Coronavirus Outbreak in India," 2020. [Online]. Available: https://www.covid19india.org/. [Accessed: 28-Apr-2020].

6. COV-IND-19 STUDY GROUP, "Predictions and role of interventions for COVID-19 outbreak in India," 2020. [Online]. Available: https://medium.com/@ covind_19/predictions-and-roleof-interventions-for-covid-19-outbreak-in-india-52903e2544e6. [Accessed: 23-Jun-2020].

7. Datta, R.; Yadav, A. K.; Singh, A.; Datta, K.; Bansal, A.; Med. J. Armed Forces India, 2020.

8. MoHFW, "Guide to address stigma associated with COVID-19," GoI. [Online]. Available: https://www.mohfw.gov.in/pdf/ GuidetoaddressstigmaassociatedwithCOVID19.pdf. [Accessed: 17Jun-2020].

9. MoHFW, "Addressing social stigma associated with COVID-19," GoI, 2020. [Online]. Available: https://www.youtube.com/watch? v=1GCv8_BIWeY\&feature=youtu.be. [Accessed: 17-Jun-2020].

10. Babar, K.; "Covid19 Impact: Realtors' body NAREDCO urges for \$ 200 billion package for economy," The Economic Times, 2020. [Online]. Available: https://economictimes.indiatimes.com/ industry/indl-goods/svs/construction/realtors-body-naredco-urgesgovt-for-200-billion-package-to-deal-with-covid19impact/printarticle/75059305.cms. [Accessed: 25-Apr-2020].

11. "FM announces Construction Workers' Fund," Construction World, 2020. [Online]. Available: https://www.constructionworld.in/LatestUpdates-On-Construction-Companies/FM-announcesConstruction-Workers-Fund/23377. [Accessed: 26-Apr-2020].

12. GoI, "Labour Ministry Issues Advisory to all States / UTs to use Cess fund for Welfare of Construction Workers," Press Release Page, 2020.[Online].Available: https://pib.gov.in/PressReleasePage.aspx? PRID=1607911. [Accessed: 29-Apr-2020].

13. "Construction World," 2020. [Online]. Available: https://www.constructionworld.in/. [Accessed: 29-Apr-2020].

14. "Roads to Recovery-Webinar," Construction World, 2020. [Online]. Available: https://www.constructionworld.in/webinar\#21april. [Accessed: 30-Apr-2020].
15. PTI, "Realty players fear pay cuts, job losses as lockdown hits revenue," The Economic Times, 2020. [Online]. Available: https://economictimes.indiatimes.com/industry/indl-goods/svs/ construction/realty-players-fear-pay-cuts-job-losses-as-lockdownhits-revenue/articleshow/75123027.cms?from=mdr. [Accessed: 24 Apr-2020].

16. TNN, "Builders worried about cement becoming unusable," 2020 [Online]. Available: https://realty.economictimes.indiatimes.com/ news/industry/builders-worried-about-cement-becoming-unusable/ 75398766. [Accessed: 29-Apr-2020].

17. PTI, "SBI to raise Rs 200 bn for affordable housing, infrastructure projects," Business Standard, 2020. [Online]. Available: https://www.business-standard.com/article/printer-friendlyversion?article_id=118011701161_1. [Accessed: 25-Apr-2020].

18. E. Online, "Real estate investment drops $58 \%$ in January - March 2020: Report," The Economic Times. [Online]. Available: https://economictimes.indiatimes.com/industry/services/property-/cstruction/real-estate-investment-drops-58-in-januarymarch-2020report/printarticle/75248985.cms. [Accessed: 20-Apr-2020].

19. P. Padode, "An open letter," Construction World, 2020. [Online]. Available: https://www.constructionworld.in/digital-edition/desk/An-Open-Letter-/23397. [Accessed: 29-Apr-2020].

20. CMIE, "Impact of the lockdown on industrial production," CMIE, 2020. [Online]. Available: https://www.cmie.com/kommon/ $\mathrm{bin} / \mathrm{sr}$.php?kall=warticle \&dt=2020-04-18 $\quad 16: 24: 49 \& \mathrm{msec}=933$. [Accessed: 04-May-2020].

21. Li, Q.; et al., N. Engl. J. Med., 2020, 382, 1199.

22. Koh, D.; Occup. Med. (Chic. Ill)., 2020, 70, 3.

23. Eliza Wong, E. Y.; Ho, Kin-fai; Wong, Samuel; Cheung, Annie; "Workplace safety and coronavirus disease (COVID-19) pandemic: Survey of employees," 2020.

24. C. E. S.; Anshuman Mishra, A. T.; Patra, Santanu; Shukla, Sudheesh K.; Pandey, Pavan; Shukla, Yogesh; Osmera, Pavel; Yadav, Pankaj; Pandey, Manoj; Gupta, Rajiv; Molina, Franck; Adv. Mater. Lett., 2020, 11,1 .

25. Zhai, Z.; Build. Environ. Elsevier, 2020

26. Centers for Disease Control and Prevention, "How COVID-19 Spreads," CDC, 2019. [Online]. Available: https://www.cdc.gov/ coronavirus/2019-ncov/prevent-getting-sick/how-covidspreads.html?CDC_AA_refVal=https $\% 3 \mathrm{~A} \% 2 \mathrm{~F} \% 2 \mathrm{Fwww} . c d c . g o v$ $\% 2$ Fcoronavirus \%2F2019-ncov\%2Fprepare\%2Ftransmission.html. [Accessed: 24-Apr-2020].

27. Cook, T. M.; "Personal protective equipment during the COVID-19 pandemic - A narrative review," Anaesthesia, 2020.

28. Pisharody, R. V.; "Questions in wake of Vizag gas leak: 'What caused the leak, did people know they lived in vulnerable zone?," The Indian Express, 2020. [Online]. Available: https://indianexpress.com/article/cities/hyderabad/questions-inwake-of-vizag-gas-leak-what-caused-the-leak-did-people-knowthey-lived-in-vulnerable-zone-6398871/. [Accessed: 09-May-2020].

29. Sharma, A. K.; "Developers can resume construction of real estate projects in some areas," Livemint, 2020. [Online]. Available: https://www.livemint.com/news/india/developers-can-resumeconstruction-of-real-estate-projects-in-some-areas11586952379253.html. [Accessed: 01-May-2020].

30. Belingheri, M.; Paladino, M. E.; Riva, M. A.; Occup. Med. (Chic. Ill), 2020, 70, 82 .

31. Chu, D. K.; et al., Lancet (London, England), 2020, 6736, 1.

32. NARDECO, "Standard Operating Procedures (SOPs) and Guidelines for Construction Sites for COVID-19 Outbreak." [Online]. Available: http://naredco.in/pdfs/COVID-19-SOPsGuidelines.pdf. [Accessed: 02-May-2020].

33. GoI, "COVID-19: Guidelines on disinfection of common public places including offices," MOHFW, 2020. [Online]. Available: https://www.mohfw.gov.in/pdf/Guidelinesondisinfectionofcommon publicplacesincludingoffices.pdf. [Accessed: 02-May-2020].

34. BOMMA, "Getting Back to Work: Preparing Buildings for Re-Entry Amid COVID-19,” 2020. [Online]. Available: https://boma.informz.net/BOMA/data/images/Getting Back To Work Preparing Buildings for Re Entry.pdf. [Accessed: 03-May2020].

35. "Guidance For Cleaning \& Disinfecting," CDC, 2020. [Online]. Available: https://www.cdc.gov/coronavirus/2019-ncov/ 


\section{Advanced Materials Letters www.vbripress.com/aml}

community/pdf/ReOpening_America_Cleaning_Disinfection_Deci sion_Tool.pdf. [Accessed: 04-May-2020].

36. "Construction Sector - Site Operating Procedures Protecting Your Workforce During Coronavirus (Covid-19)," Construction Leadership Council, 2020. [Online]. Available: https://builduk.org/ wp-content/uploads/2020/03/Site-Operating-Procedures.pdf. [Accessed: 01-May-2020].

37. Chetterje, P.; Lancet. Infect. Dis., 2020, 20, 544.

38. Coil, D. A.; Fretz, M.; mSystems, 2020, 1.

39. Chan, J. F. W.; et al., Lancet, 2020, 395, 514

40. A. T. et al. an Doremalen, Neeltje, Trenton Bushmaker, Dylan H. Morris, Myndi G. Holbrook, Amandine Gamble, Brandi N. Williamson, N. Engl. J. Med., 2020, 1.

41. Z. Company, "Terminology: Virus Infectivity Titer Pertaining to Virus Infectivity Titer." [Online]. Available: https://www. zeomic.co.jp/en/glossary/virus/70. [Accessed: 15-Jun-2020].

42. Suman, R.; Javaid, M.; Haleem, A.; Vaishya, R.; Bahl, S.; Nandan, D.; J. Clin. Exp. Hepatol., 2020.

43. Zeomic Company, "Terminology: TCID50(Median Tissue Culture Infectious Dose)." [Online]. Available: https://www.zeomic.co.jp/ en/glossary/virus/71. [Accessed: 15-Jun-2020].

44. "Table: HIV RNA viral load log value - number conversion." [Online]. Available: https://i-base.info/log-value-conversion-table/. [Accessed: 15-Jun-2020].

45. Ferrand, H. Le; MRS Bull., 2020, 45, 327.

46. Farmer, M.; "The Farmer Review of the UK Construction Labour Model," Construction Leadership Council, 2016. [Online]. Available: https://www.gov.uk/government/publications/ constructionlabour-\%0Amarket-in-the-uk-farmer-review.

47. Khan, N.; "We have designed a 400- bed hospital that can be built in 2 weeks," 2020. [Online]. Available: https://assets2.katerra.com/wpcontent/uploads/sites/3/2020/05/15091730/ct-may-2020-Nejeeb. pdf. [Accessed: 05-Jun-2020].

48. Padode, P.; "CW Webinar: Construction Technologies Post COVID-19 Up next," Construction World, 2020. [Online]. Available: https://www.youtube.com/watch?v=7uvbp67CtEc\&t= 394s. [Accessed: 01-Jun-2020].

49. Montazer, M.; Harifi, T.; Antibacterial Nanocoatings, Elsevier, 2020, 99.

50. Shah, K. W.; Lu, Y.; Constr. Build. Mater., 2018, 180, 544.

51. Luo, C.; James, D.; Loma, A.; Ormonde, A.; "Building Materials With Boresistant Properties," US 2005/0126430 A1, 2005.

52. Elgohari, T.; "Visual Comparison between the Traditional and the 4D BIM approach in project management.," LinkedIn, 2016. [Online]. Available: https://www.linkedin.com/pulse/visualcomparison-between-traditional-4d-bim-approach-tamer-elgohari.

53. Gupta, R.; Construction Planning and Technology, 2nd Ed. CBS Publishers, 2013.

54. Padode, P.; "Effect of CoronaVirus in Construction Manufacturing Industry," Construction World, 2020. [Online]. Available: https://www.youtube.com/watch?time_continue=75\&v=ThjAivJV7 0Q\&feature=emb_logo. [Accessed: 01-May-2020].

55. Kumar, N.; " 1,000 foreign $\mathrm{rms}$ mull production in India, 300 actively pursue plan as 'Exit China' mantra grows," Business Today, 2020. [Online]. Available: https://www.businesstoday.in/current/ economy-politics/1000-foreign-firms-mull-production-in-india300-actively-pursue-plan-as-exit-china-mantra-grows/story/ 401462.html?utm_source=recengine\&utm_medium=WEB\&referra 1_sourceid=400728\&referral_cat=World. [Accessed: 28-Apr-2020].

56. "Government in big push towards digital sales in realty," Bureau Bangalore Mirror, 2020. [Online]. Available: https://bangaloremirror.indiatimes.com/news/india/government-inbig-push-towards-digital-sales-in-realty/articleshowprint/75212493. cms?prtpage $=1$. [Accessed: 28-Apr-2020]. 